\title{
Dual-Source Optimization of the "Diverting Water from the Yangtze River to Tai Lake (DWYRTL)" Project Based on the Euler Method
}

\author{
Ruichen Xu $\mathbb{D}^{1,2}$ Yong Pang $\left.{ }^{1}\right)^{1,2}$ Zhibing Hu, ${ }^{1,2}$ and John Paul Kaisam ${ }^{1,2,3}$ \\ ${ }^{1}$ Key Laboratory of Integrated Regulation and Resource Development on Shallow Lakes, Ministry of Education, Hohai University, \\ Nanjing 210098, China \\ ${ }^{2}$ College of Environment, Hohai University, Nanjing 210098, China \\ ${ }^{3}$ Department of Chemistry, School of Environmental Sciences, Njala University, Freetown, Sierra Leone
}

Correspondence should be addressed to Ruichen Xu; 1349439798@qq.com and Yong Pang; ypang@hhu.edu.cn

Received 12 May 2020; Revised 27 June 2020; Accepted 16 July 2020; Published 4 August 2020

Guest Editor: Tongqian Zhang

Copyright (C) 2020 Ruichen Xu et al. This is an open access article distributed under the Creative Commons Attribution License, which permits unrestricted use, distribution, and reproduction in any medium, provided the original work is properly cited.

\begin{abstract}
Appropriate water body diversion can improve the water quality of Tai Lake. Excessive diversion of water would, however, dramatically alter the local flow fields, which are not conducive to the growth of aquatic plants and the stability of ecosystems. The current "Diverting Water from the Yangtze River to Tai Lake (DWYRTL)" project uses a single water source, the Wangyu River, for diversion, a model that may significantly affect the nearby flow rate or uniformity of the lake and is not conducive to the longterm stability of the aquatic ecosystem in the Tai Lake district of the eastern part of the lake. In order to simulate the different situations of single- and dual-source water diversions (Wangyu-Xinmeng Rivers) in Tai Lake, we based this study on a threedimensional hydrodynamic model coupled with the Euler method, which can accurately calculate the water exchange rates in the different districts of Tai Lake. The results show that (1) it is recommended that the total annual diversion of water should not exceed $20 \times 10^{8} \mathrm{~m}^{3}$; (2) the wind field is the most important factor determining the distribution of spatial water exchange; (3) under wind-free conditions, the flow rate of a single-source diversion of water is approximately $50 \%$ higher than that of dualsource diversion; and (4) water diversion under the prevailing conditions of the northwest wind in winter will reduce the semiexchange period of the eastern part of the lake area from 50 to 30 days, significantly changing the nearby district's uniformity, leading to ecological risks. Therefore, it is recommended that the dual-source water diversion mode be used in winter and windless season, and single-source water diversion mode be used in other seasons.
\end{abstract}

\section{Introduction}

Diverting water from the Yangtze River to Tai Lake (DWYRTL) is one of the major water conservation projects in the Tai Lake Basin. This diversion supplies a large amount of water resources to downstream areas including the city of Shanghai and Zhejiang Province while serving as one of the essential basic projects for social and economic development in the Yangtze River Delta [1]. However, the continuous increase in downstream water demand, the overflow rate, and the water exchange uniformity (WEU) index [2] will have a certain adverse effect on the stability of the aquatic ecosystem. In particular, the East Lake District forms the region with the most complete aquatic ecosystem that can only be sustained by relying on diversion of the Wangyu River alone. The Wangyu River is very close to the district that is most sensitive to changes in hydrology, and an excessive diversion of water from the Wangyu River will have a significant impact on the East Lake District [3]. An uneven mixing of water bodies will also change the original aquatic environment, thereby reducing the survival rate of aquatic vegetation $[4,5]$. Many scholars have found that cyanobacterial blooms will be directly affected by hydrodynamic forces and pollutant fluxes caused by water diversion $[6,7]$. 
Therefore, further research and discussion are needed to determine whether this risk can be mitigated by the Wangyu-Xinmeng River dual-source diversion method.

At present, researchers have mainly used on-site monitoring and hydrodynamic models to study the flow velocity of water bodies. On-site monitoring may provide measured field data and basic boundary conditions for a hydrodynamic model. A hydrodynamic model can predict and compare different future scenarios quantitatively [8]. The exchange of water in a water body is mainly reflected by the water exchange rate and the semiexchange cycle [9]. Currently, water body exchange studies have mainly been conducted using the Lagrange method and the Euler method [10]. Based on a three-dimensional unsteady state model, Luff and Pohlmann [11] used the Lagrange method to study the exchange of water between water bodies (e.g., flushingtime, turn-over time, and half-life time) in the North Sea. However, the Lagrange method ignores the convective diffusion of water $[12,13]$. By contrast, Euler's Method uses a conservative method, namely, a coupled convective diffusion model, to simulate the water body exchange in a local area [14].

Based on a current tidal model, Xie et al. [15] simulated the exchange of water in water bodies on an impounded lake in Taipingwan Port of Dalian, Liaoning Province, China. The simulation suggested that the construction of a submerged dike would hinder the exchange of water between water bodies, i.e., the elevation of the underwater soil would have a significant impact on the exchange capacity of regional water. Dai et al. [16] used an unstable state model to analyze the exchange of water bodies between Dongting Lake and Yangtze River before and after the implementation of the Three Gorges Project. Dai and colleagues have identified a significant change in the amount of water entering and exiting the lake and documented an extended period of water body exchange during the postconstruction phase. Based on the three-dimensional Euler algorithm of the Environmental Fluid Dynamics Code, Xu et al. [17] examined the exchange of water between water bodies in urban man-made lakes and obtained good results for some recently completed projects through optimizations. Water body exchange research based on the Euler method can, therefore, more intuitively and accurately reflect the unique influence of water diversion on the exchange of water between water body in a large scale and local areas of Tai Lake.

Most of the studies on the DWYRTL project only considered a single-source water diversion model, which may lose another viable solution if the demand for water resources is met, but a dual-source diversion may be able to resolve the related problems [18]. Among them, Li et al. [19] analyzed the relationship between the diversion of the Wangyu River and the hydrodynamic conditions of Tai Lake, determined the basic hydrodynamic parameters of Tai Lake, and optimized the economic applicability of the water diversion project. During the implementation of WDYRTL in the Wangyu River basin, Yang et al. [20] revealed that short-term water diversion would cause a deterioration in the quality of water in the Gong Bay area. Qing [21] adopted a two-dimensional unsteady state model to assess the hydrodynamic conditions and water quality of the Taihu River after the diversion of water from the Xinmeng River to Tai Lake. The study suggested that the diversion of the Xingeng River would improve the aquatic environment of Tai Lake, but comprehensive control would be needed to prevent the most negative effects of single-channel drainage on the quality of water in the Yangtze River. Yong [22] studied the environmental changes of Tai Lake after the diversion of the Xingeng River. The study not only found that the aquatic environment improved in the Northwest Lake District but also documented the relatively poor water diversion efficiency from the Yangtze River and the associated water diversion management conditions. In general, there are still some drawbacks with regard to the optimization of dualsource water diversion in different situations.

This study involved the construction of a three-dimensional hydrodynamic mathematical model based on the measured data acquired from 2017 to 2018 . The changes in nearby flow velocity were studied and analyzed using different diversion models and scales. The calculation of the water exchange rate and the semiexchange period for eight wind field conditions prevailing at different time periods was coupled with the Euler algorithm during the analysis. The calculation of the water exchange rate and semiexchange period of the eight main districts of Tai Lake were expected to be obtained, and a more in-depth study of the difference and linkages between single-source diversion and dual source diversion should continue in order to provide a scientific reference for future diversion strategies. The paper mainly discusses (1) the research area, (2) the research method, (3) results and discussion, and (4) conclusions.

\section{Study Area}

Tai Lake, located at the lower reaches of the Yangtze River Basin $\left(119^{\circ} 08^{\prime}-122^{\circ} 55^{\prime} \mathrm{E}, 30^{\circ} 05^{\prime}-32^{\circ} 08^{\prime} \mathrm{N}\right)$, covers an area of $2,338 \mathrm{~km}^{2}$ to a maximum water depth of up to $3 \mathrm{~m}$. This typical large shallow lake [23] has been previously divided into three lake bay districts and five major water areas in order to accurately analyze the water exchange characteristics of the various areas of the lake [24]. Using data downloaded from the China Meteorological Data Network (http://data.cma.cn/), in the last decade, Tai Lake was mainly affected by the easterly winds in autumn and mainly affected by the southeastern and northwestern monsoons in springsummer and winter, respectively (Figure 1). According to the Tai Lake Basin Authority, Ministry of Water Resources (http://www.tba.gov.cn/), the DWYRTL project consists mainly of the Xinmeng River Extension Project, the Xingou River Extension Project, and the Wangyu River Project, where the first and last of these projects directly divert water from the Yangtze River into Tai Lake. In the last decade, the average annual water intake was 7.5 billion $\mathrm{m}^{3}$, with the main water diversion periods occurring between JanuaryMarch, July-August, and October-December and the longest continuous water diversion period being 90 days [16]. 


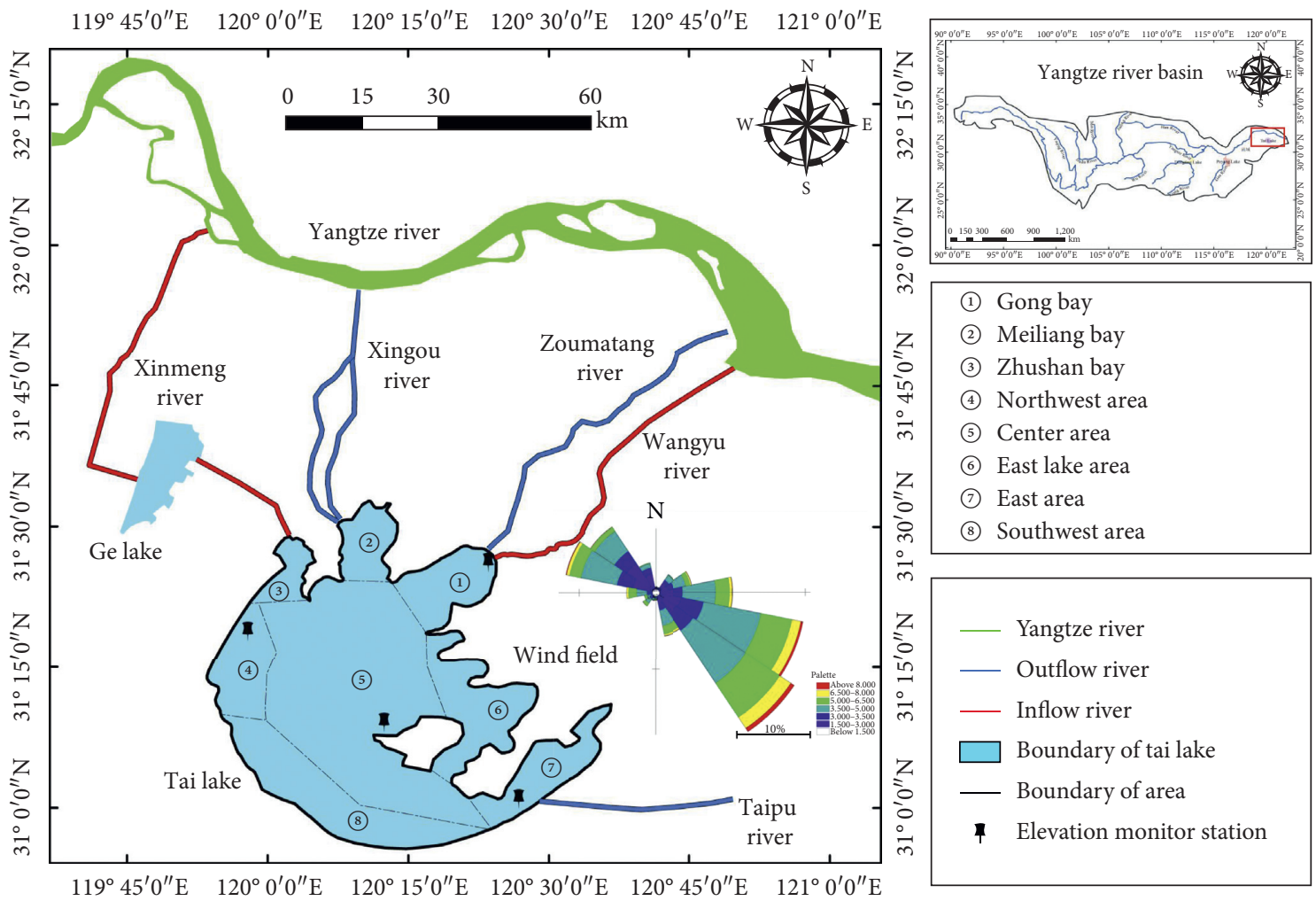

Figure 1: Map showing the location of water diversion from the Yangtze River to Tai Lake project. An inset map shows the location of the study area within China.

From 1990 to 2017, the amount of water diverted from the Yangtze River to the west of the Wangyu River increased annually [25], with the annual amount of water diversion increasing from 1.6 billion $\mathrm{m}^{3}$ to 5.2 billion $\mathrm{m}^{3}$ during this period-an increase of $225 \%$ (Figure 2). Over the same period, the total amount of water entering the lake also increased, while the number of days of water exchange in Tai Lake decreased correspondingly year-on-year, from 266 days to 160 days, by $39.8 \%$.

\section{Methodology}

3.1. 3D Hydrodynamic Model. To accurately calculate the volume of water body exchange, this study employed a hydrodynamic model used in this study that is based on the Navier-Stokes equations of three-way incompressible flow and Reynolds values and was subject to the assumption of Boussinesq and hydrostatic pressure. The finite volume method was applied to calculate the spatial discretization. Its mathematic expression is shown in the equations below [26].

The water flow continuity equation is given by the following equation:

$$
\frac{\partial u}{\partial x}+\frac{\partial v}{\partial y}+\frac{\partial w}{\partial z}=S .
$$

The Navier-Stokes equations for horizontal momentum in the $X$ and $Y$ directions are shown in equations (2) and (3), respectively:

$$
\begin{aligned}
& \frac{\partial u}{\partial t}+\frac{\partial u^{2}}{\partial x}+\frac{\partial v u}{\partial y}+\frac{\partial w u}{\partial z}=f v-g \frac{\partial \eta}{\partial x}-\frac{1}{\rho_{0}} \frac{\partial P_{a}}{\partial x}- \\
& \frac{g}{\rho_{0}} \int_{z}^{\eta} \frac{\partial p}{\partial x} \mathrm{~d} z-\frac{1}{\rho_{0} h}\left(\frac{\partial s_{x x}}{\partial x}+\frac{\partial s_{x y}}{\partial y}\right)+F_{u}+\frac{\partial}{\partial z}\left(v_{t} \frac{\partial u}{\partial z}\right)+u_{s} S,
\end{aligned}
$$

$$
\begin{aligned}
& \frac{\partial v}{\partial t}+\frac{\partial v^{2}}{\partial x}+\frac{\partial v u}{\partial y}+\frac{\partial w v}{\partial z}=f v-g \frac{\partial \eta}{\partial x}-\frac{1}{\rho_{0}} \frac{\partial P_{a}}{\partial x}- \\
& \frac{g}{\rho_{0}} \int_{z}^{\eta} \frac{\partial p}{\partial x} \mathrm{~d} z-\frac{1}{\rho_{0} h}\left(\frac{\partial s_{y x}}{\partial x}+\frac{\partial s_{y y}}{\partial y}\right)+F v+\frac{\partial}{\partial z}\left(v_{t} \frac{\partial v}{\partial z}\right)+v_{s} S,
\end{aligned}
$$

where $t$ represents time; $x, y$, and $z$ are the Cartesian coordinates; $u, v$, and $w$ are the components of velocity along the $x, y$, and $z$ coordinate directions, respectively; $f_{u}$ and $f_{v}$ are the Coriolis accelerations along the $X$ and $Y$ coordinate directions; $f=2 \Omega$ sin $\varphi$ represents the Coriolis factor ( $\Omega$ is the angular velocity of the Earth's rotation, and $\varphi$ is the geographic latitude); $g$ is the acceleration of gravity; $\eta$ represents the water level; $\rho_{0}$ and $\rho$ represent the density of air and water, respectively; $P_{a}$ is the atmospheric pressure; $h$ represents the total water depth; $S_{x x}, S_{x y}$, and $S_{y y}$ are the radiation stress tensors; $v_{t}$ is the vertical vortex viscosity coefficient; $S$ is the source-sink term; and $F_{u}$ and $F_{v}$ are the horizontal stresses along the $X$ and $Y$ coordinate directions, respectively. The flow velocity gradient-stress relationships can be expressed by 


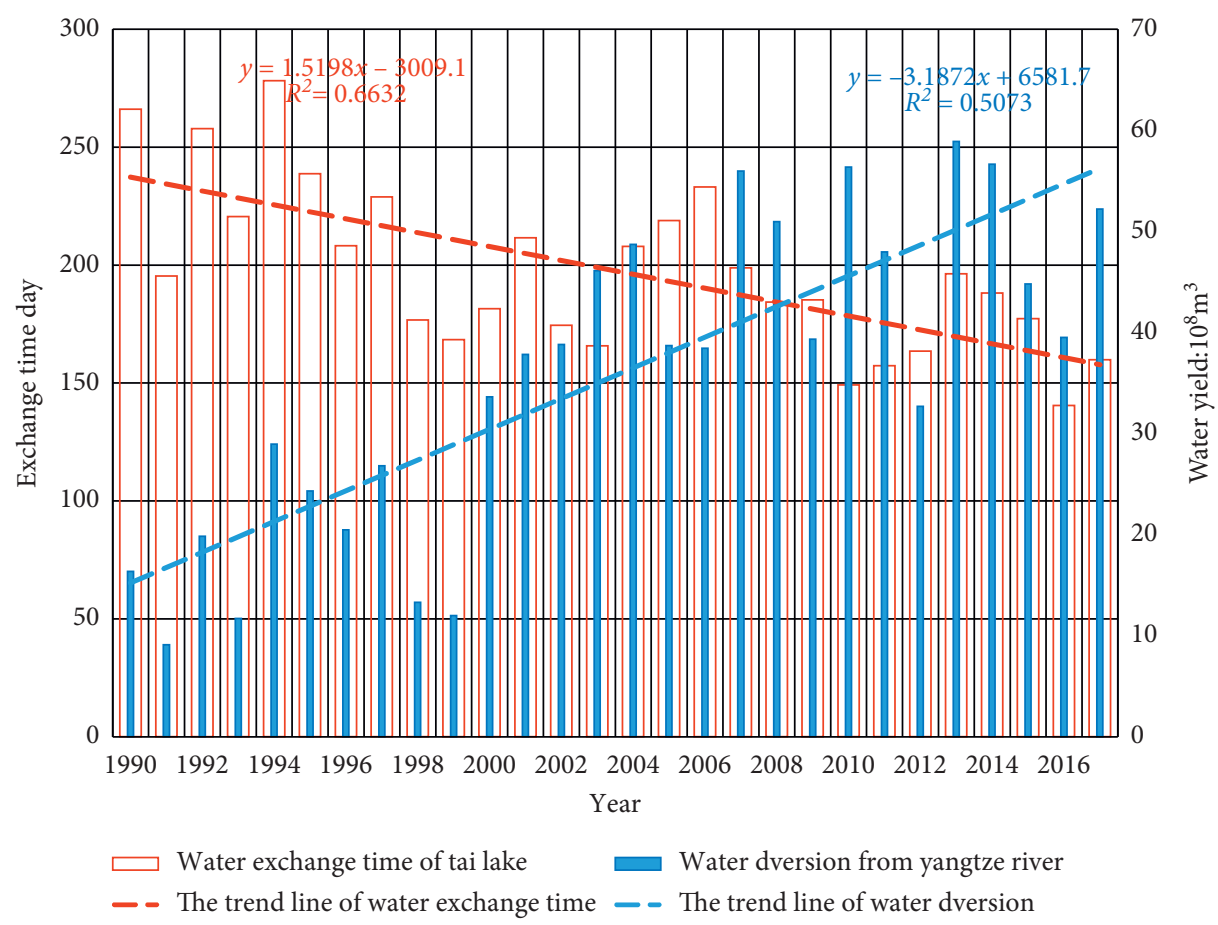

Figure 2: Trends in the amount of water entering Tai Lake from 1990 to 2017 and its water body exchange time.

$$
\begin{aligned}
& F_{u}=\frac{\partial}{\partial x}\left(2 A \frac{\partial u}{\partial x}\right)+\frac{\partial}{\partial x}\left(A\left(\frac{\partial u}{\partial y}+\frac{\partial v}{\partial x}\right)\right), \\
& F_{v}=\frac{\partial}{\partial y}\left(2 A \frac{\partial v}{\partial y}\right)+\frac{\partial}{\partial x}\left(A\left(\frac{\partial u}{\partial y}+\frac{\partial v}{\partial x}\right)\right),
\end{aligned}
$$

where $A$ is the horizontal eddy viscosity coefficient.

3.2. Convective Diffusion Model. To simulate the water exchange more intuitively and accurately, we use a convective diffusion model based on the Euler method, given by [27], as seen in equation (5):

$$
\frac{\partial(h C)}{\partial t}+\frac{\partial(u h C)}{\partial x}+\frac{\partial(v h C)}{\partial y}=\frac{\partial}{\partial x}\left(E_{x} h \frac{\partial C}{\partial x}\right)+\frac{\partial}{\partial y}\left(E_{y} h \frac{\partial C}{\partial y}\right)+S,
$$

where $C$ is the contaminant concentration; $E_{x}$, and $E_{y}$ are the diffusion coefficients in the $X$ and $Y$ directions, respectively. According to the Elder empirical formula, it can be known that

$$
\begin{aligned}
& E_{x}=\frac{5.93 \sqrt{g} n|h u|}{h^{1 / 6}}, \\
& E_{y}=\frac{5.93 \sqrt{g} n|h v|}{h^{1 / 6}},
\end{aligned}
$$

where $n$ is the Manning coefficient.

3.3. Water Body Exchange Research Methods. A dissolved conservation substance with an initial concentration of $100 \mathrm{mg} / \mathrm{L}$ was placed in the lake body (note that the initial concentration in the lake water was zero). After a certain period of convective diffusion, the ratio of the total amount of the remaining substance in the various areas of Tai Lake to the total amount of the initial substance is the water exchange rate of the region at that moment as shown in equation (7). An exchange rate that reaches $50 \%$ of the time is the semiexchange period [28].

$$
\operatorname{EX}\left(t_{j}\right)=1-\left[\frac{\sum_{i=1}^{M} C_{i}\left(t_{j}\right) H_{i}\left(t_{j}\right)}{\sum_{i=1}^{M} C_{i}\left(t_{0}\right) H_{i}\left(t_{0}\right)}\right] \times 100 \%,
$$

where EX is the water exchange rate; $H$ is the water depth; $i$ is the grid number in the calculated area; and $j$ is the specific time number.

Based on the constructed model, we will extract the nodes and grids of different districts (taking Gong Bay as an example), calculate the local water exchange rate, and then, determine the semiexchange period of different districts under this scenario through the water exchange method (Figure 3).

\section{Results and Discussions}

4.1. Determining the Model Parameter Rates. In order to ensure that the constructed hydrodynamic model can meet the research needs of water body exchange studies, the water body was divided into 9422 nonstructural grids with a spatial resolution of $300 \mathrm{~m}$; data acquired from 2017 to 2018 were employed. After calibration and verification of the depth of the lake, measurements of the coefficient of turbulence, the height of the bottom friction, and the wind drag coefficient were estimated at $0.28,0.02 \mathrm{~m}$, and $0.003 \mathrm{~m}$, respectively. The simulation results were well aligned with the measured water 


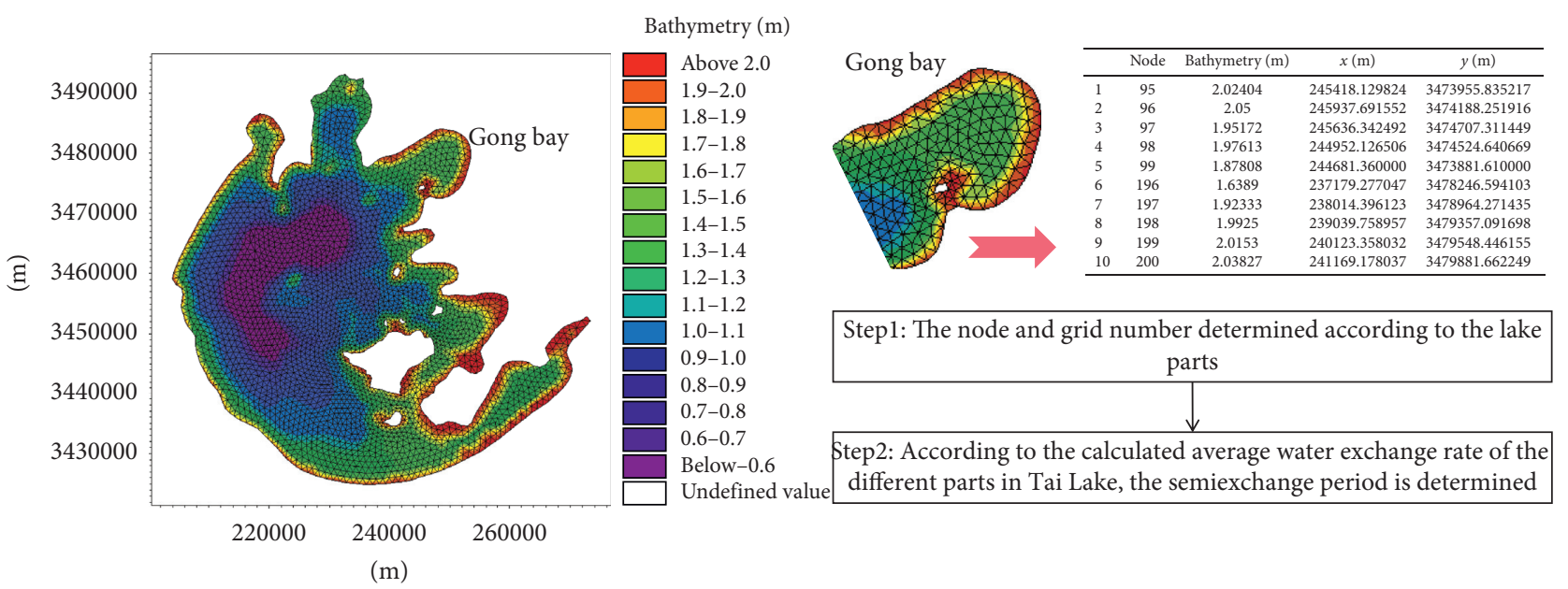

FIgURE 3: Two-step approach used to calculate the semiexchange period of Tai Lake using bathymetry data.

level at each monitoring station (Figure 4). The flow field structure simulated by the southeast and northwest monsoons at a speed of $5 \mathrm{~m} / \mathrm{s}$ had exactly the same circulation shape as the measured results (Figure 5). The results in direction and velocity of circulation flow were also consistent with the results reported in previous studies [29].

In order to further compare the simulated water levels with the measured values, this study uses three model evaluation methods, namely, average relative error (MRE), root mean square error (RMSE), and correlation coefficient analysis $\left(R^{2}\right)$. The evaluation process involves an error and correlation analysis of the measured values $(M)$ and simulated values $(S)$ with the following formulations [30]:

$$
\begin{aligned}
\text { RMSE } & =\sqrt{\frac{1}{N} \sum_{i=1}^{N}\left(S_{i}-M_{i}\right)^{2},} \\
\mathrm{MRE} & =\frac{1}{N} \sum_{i=1}^{N}\left|S_{i}-M_{i}\right|, \\
R^{2} & =\frac{\sum_{i=1}^{N}\left(S_{i}-\bar{S}\right)\left(M_{i}-\bar{M}\right)}{\sqrt{\sum_{i=1}^{N}\left(S_{i}-\bar{S}\right)^{2} \sum_{i=1}^{N}\left(M_{i}-\bar{M}\right)^{2}}},
\end{aligned}
$$

where $N$ is the number of times of total simulation; $i$ is the number of times of simulation; $S_{i}$ is the value of the $i$ th simulation; $M_{i}$ is the value of the $i$ th measurement; $\bar{S}$ is the simulated average value; and $\bar{M}$ is the measured average value.

The assessment results of the four stations (Table 1) show that the simulated water levels fit well with the measured water levels (the highest water level error $<0.09 \mathrm{~m}$ ). Simulation results can account for more than $90 \%$ of the actual situation. As a result, the constructed hydrodynamic model met the requirements for subsequent water body exchange research.

4.2. Optimizing the DWYRTL Project. Wind field conditions (i.e., windless and $5 \mathrm{~m} / \mathrm{s}$ in either easterly, southeasterly, or northwesterly directions) were determined in accordance with the climatic conditions of Tai Lake [31]. Following the relationship between the level of flood control at Tai Lake and the ecologically accepted water level, the initial water level was set at $3.25 \mathrm{~m}$ in the model [32], while the total calculation time was set at 60 days; this depended on the average time between 2007 and 2017, with the time step at $86,400 \mathrm{~s}$. Based on these settings (Table 2), the exchange characteristics of Tai Lake under the conditions of singlesource diversion of the Wangyu River and dual-source diversion of the Wangyu and Xinmeng rivers were simulated. Also, because this simulation was primarily a comparative study, it was assumed that other external conditions remained unchanged; that is, the effects of rainfall, runoff, and evaporation were not considered separately.

Ignoring wind conditions, the simulation outputs show that Gong Bay, Center District, and East Lake District were the main areas of the water exchange operating mode (a), but the water quality of the Yangtze River was poor compared to that of the exchange area (Figure 6). In addition, dependence on a single source of water diversion from the Wangyu River would increase the concentration of water with poor quality in this region while reducing the water capacity of Tai Lake. In addition, the flow field would be subjected to frequent changes that would not be appropriate for the growth of aquatic plants and the restoration of aquatic ecosystems. The operation mode (b) would significantly reduce the effects on the flow field in the East Lake District, ensuring the stability of the ecosystem as long as the volume of water and the hydrological conditions are constant. This is true because the dual-source common diversion areas would include the water body exchange areas of Zhushan Bay and the Northwest Lake District. As an auxiliary measure, the diversion of water bodies should not be used to meet the unconditional needs of the society or the economy. Operating modes (c) and (d) indicate that when water diversion is extended to $400 \mathrm{~m}^{3} / \mathrm{s}$, approximately $45 \%$ of Tai Lake water would be exchanged within 60 days, while the Tai Lake water body exchange period under natural conditions is approximately 300 days. This suggests that this level of water body diversion has caused significant disturbances to the aquatic 


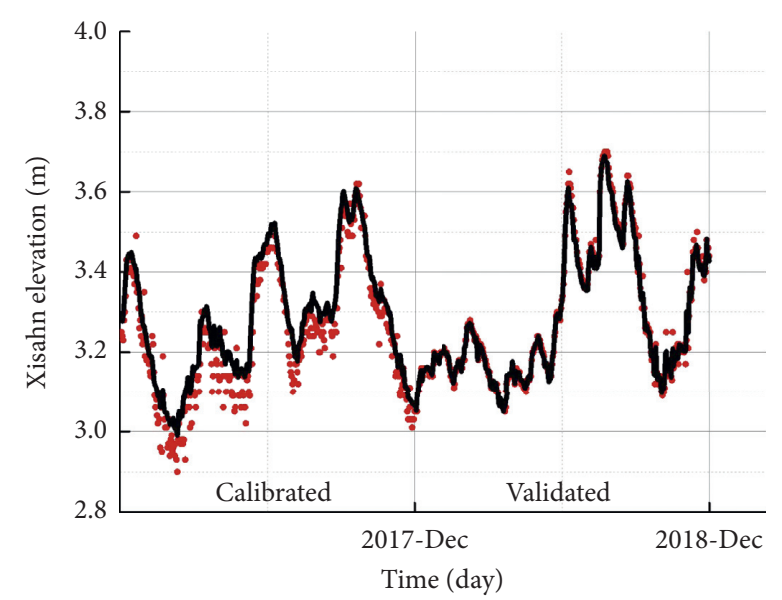

- Measured

— Simulated

(a)

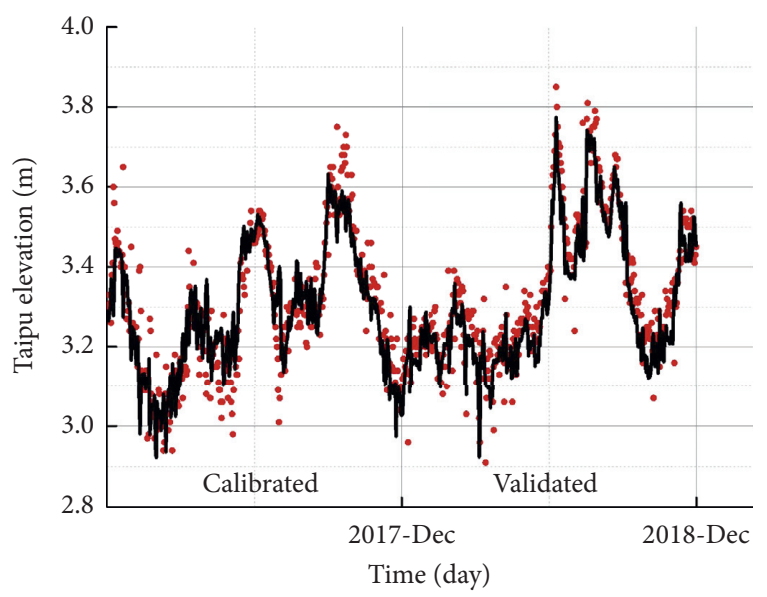

- Measured

- Simulated

(c)

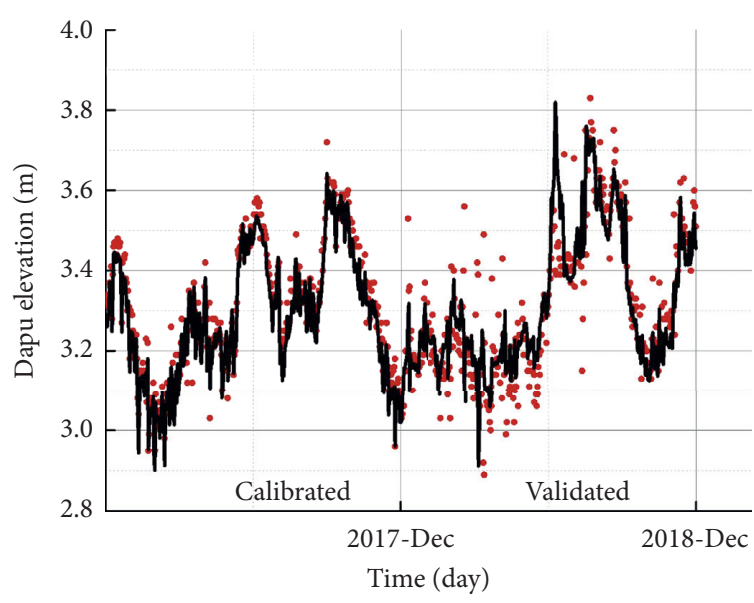

- Measured

— Simulated

(b)

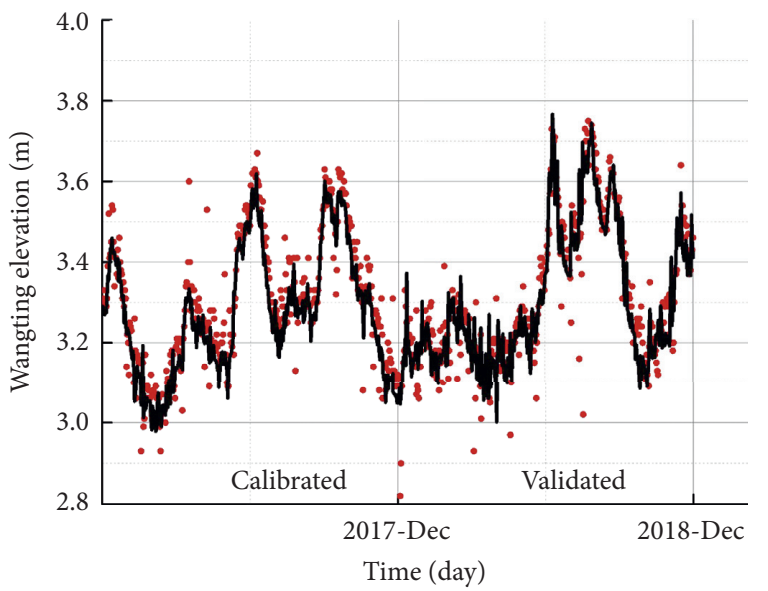

- Measured

- Simulated

(d)

FIgURE 4: Calibration and verification of surface elevation: (a) Xishan, (b) Dapu, (c) Taipu, and (d) Wangting monitoring station elevations.

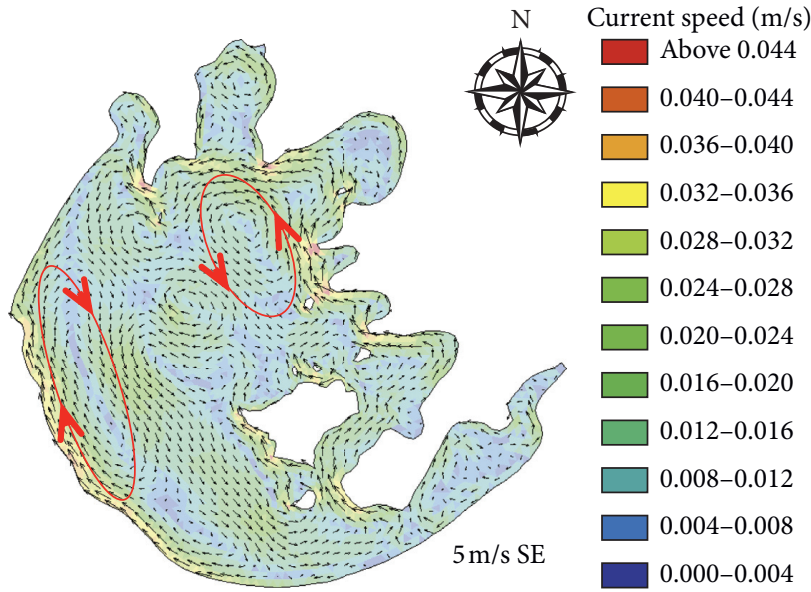

(a)

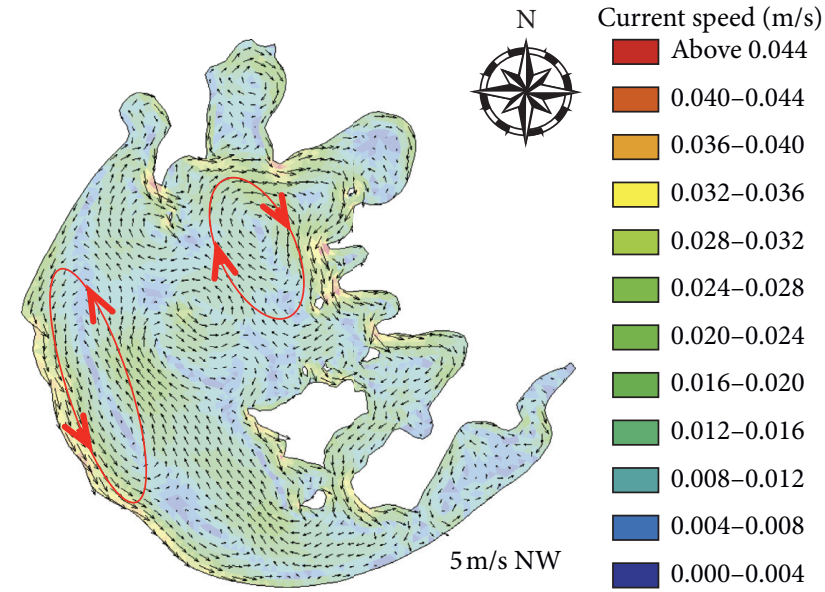

(b)

Figure 5: Verification of flow fields with winds at $5 \mathrm{~m} / \mathrm{s}$ from the (a) southeast and (b) northwest. 
TABLE 1: Model calculation evaluation.

\begin{tabular}{lcccc}
\hline Monitor & Year & RMSE & MRE (\%) & $R^{2}$ \\
\hline \multirow{2}{*}{ Xishan } & 2017 & 0.056 & 4.66 & 0.971 \\
\multirow{3}{*}{ Dapu } & 2018 & 0.018 & 3.30 & 0.995 \\
\multirow{2}{*}{ Taipu } & 2017 & 0.039 & 6.64 & 0.976 \\
\multirow{2}{*}{ Wangting } & 2018 & 0.100 & 3.51 & 0.839 \\
& 2017 & 0.049 & 6.12 & 0.968 \\
\end{tabular}

TABle 2: Simulated operating mode under different water diversion and hydrological conditions.

\begin{tabular}{|c|c|c|c|c|c|c|}
\hline Scene & Time & Wind speed $/(\mathrm{m} / \mathrm{s})$ & Wind direction & Wangyu River $/\left(\mathrm{m}^{3} / \mathrm{s}\right)$ & Xinmeng River $/\left(\mathrm{m}^{3} / \mathrm{s}\right)$ & Taipu River $/\left(\mathrm{m}^{3} / \mathrm{s}\right)$ \\
\hline $\bar{a}$ & All year & 0 & - & 200 & 0 & -200 \\
\hline $\mathrm{b}$ & All year & 0 & - & 100 & 100 & -200 \\
\hline c & All year & 0 & - & 400 & 0 & -400 \\
\hline $\mathrm{d}$ & All year & 0 & - & 200 & 200 & -400 \\
\hline e & Spring-Summer & 5 & SE & 200 & 0 & -200 \\
\hline $\mathrm{f}$ & & 5 & SE & 100 & 100 & -200 \\
\hline g & Autumn & 5 & $\mathrm{E}$ & 200 & 0 & -200 \\
\hline $\mathrm{h}$ & & 5 & $\mathrm{E}$ & 100 & 100 & -200 \\
\hline $\mathrm{i}$ & Winter & 5 & NW & 200 & 0 & -200 \\
\hline j & & 5 & NW & 100 & 100 & -200 \\
\hline
\end{tabular}

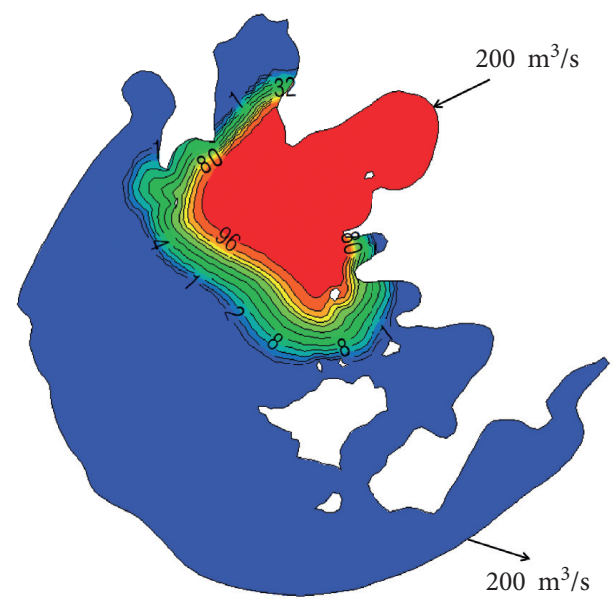

(a)

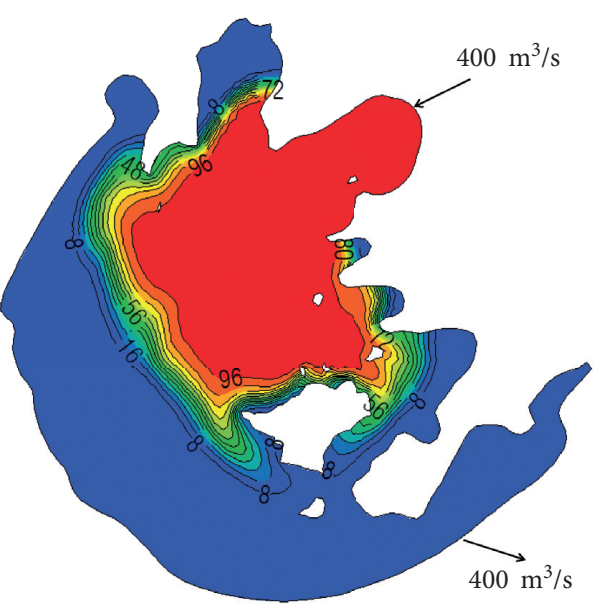

(c)

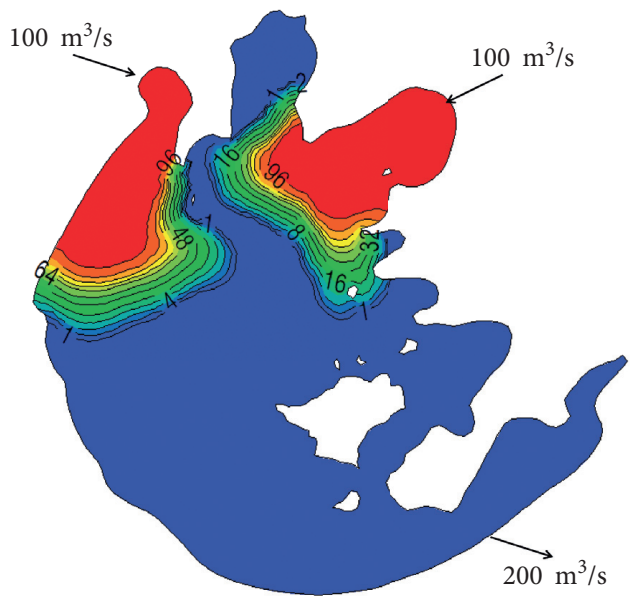

(b)

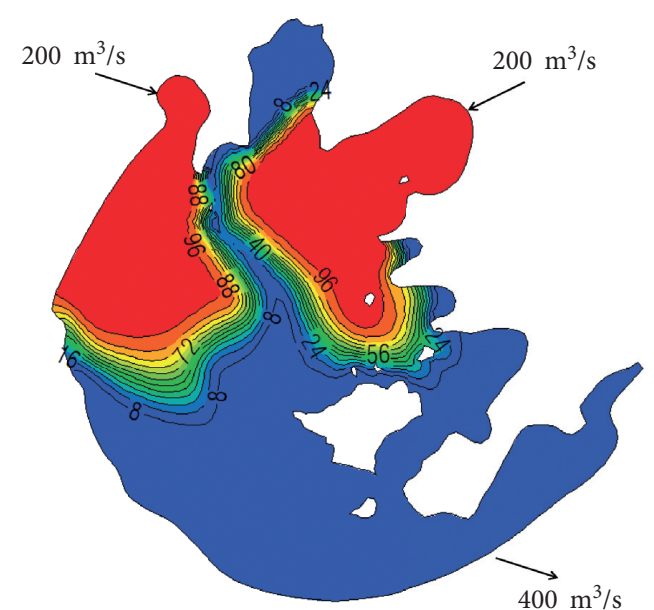

(d)

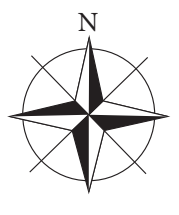

Exchange rate (\%)
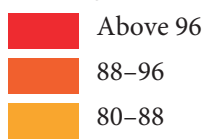

72-80

$64-72$

48-64

32-48

16-32

8-16

4-8

2-4

1-2

0-1

FIgURE 6: Simulated water body exchange rates under operating modes (a)-(d) as described in the main text. 


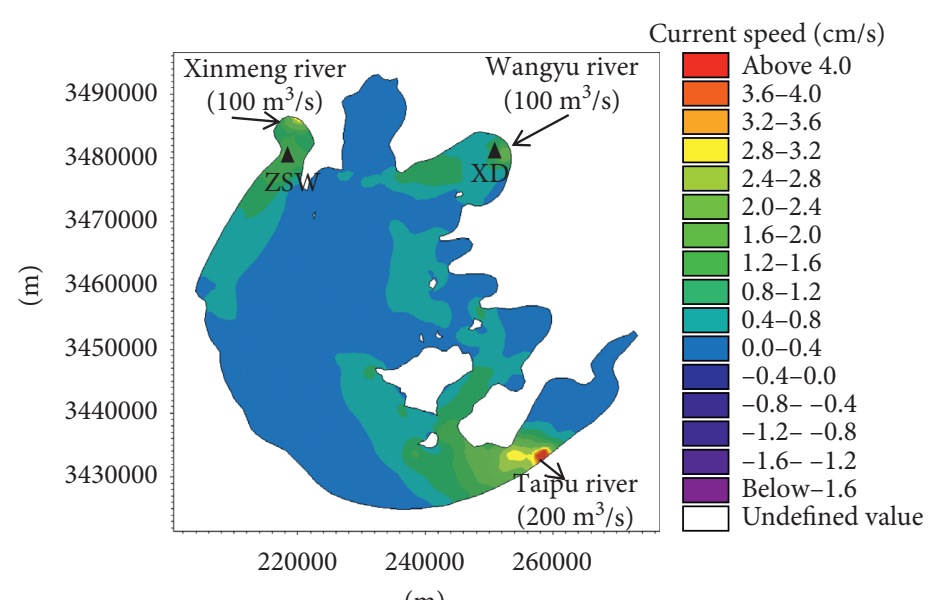

(m)

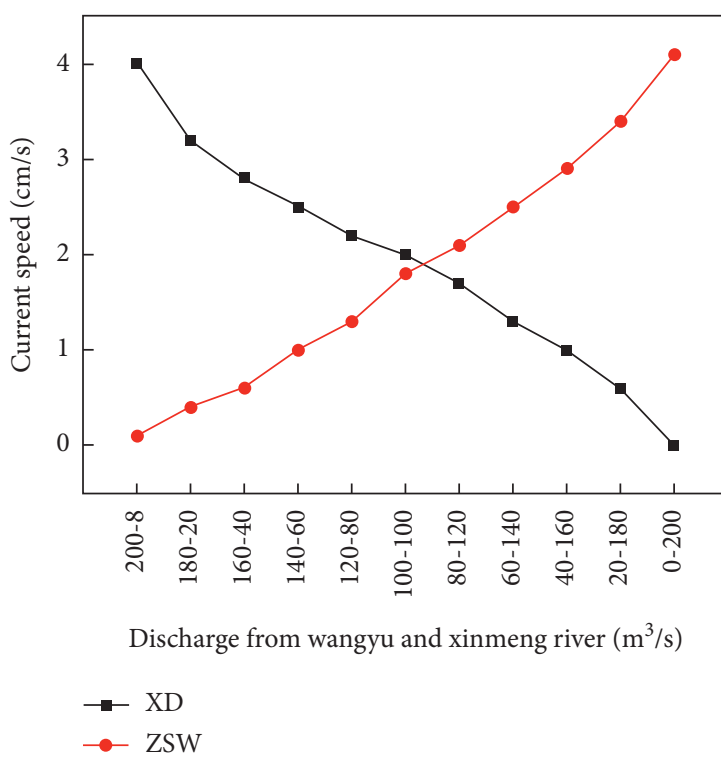

(b)

Figure 7: (a) Map of Tai Lake showing the speed of water flow, and (b) flow rates in different levels of water diversion from the Yangtze River to Tai Lake scales from the Wangyu and Xingmeng rivers.

environment of Tai Lake, which would have a serious impact on the storage capacity of Tai Lake and the stability of the aquatic ecosystem [28]. It is recommended that the total water intake in the future should not exceed $20 \%$ of the total annual lake water intake, i.e., $20 \times 10^{8} \mathrm{~m}^{3} / \mathrm{a}$.

The rate at which water flows through Tai Lake is mainly affected by the wind field and the exchange rate of water; an excessive flow rate will have a certain adverse effect on the stability of the ecosystem [33-35]. The flow field of the surrounding area will be controlled by the inflow-outflow discharge under windless conditions. Under the different diversion scales of the Wangyu and Xingeng rivers, the changes in velocity at two monitoring points, XD and ZSW, can be seen in Figure 7. From the calculation results and the change in flow rate, the flow rate of a single-source water diversion $\left(200 \mathrm{~m}^{3} / \mathrm{s}\right)$ is predicted to be approximately $50 \%$ higher than that of a dual-source water diversion $\left(100 \mathrm{~m}^{3} / \mathrm{s}\right.$ average), i.e., the best strategy under wind-free conditions is to divert water from the Wangyu and Xingeng rivers by $100 \mathrm{~m}^{3} / \mathrm{s}$. At this time, water diversion has the lowest impact on the different districts and contributes to the stability of the ecosystem [36].

The simulation results show that when the total amount of water is $200 \mathrm{~m}^{3} / \mathrm{s}$, the Tai Lake water exchange rate is approximately $20 \%$ over the four seasons, regardless of whether the water diversion method is a single- or a dualsource (Figure 8 ). This indicates that the water exchange rate is not mainly related to the amount of water entering/leaving the lake but related to the spatiotemporal distribution of the exchange of the water body, which depends primarily on the wind field [37]. This occurs because the wind field mainly determines the flow field of large shallow lakes. Singlesource water diversion is prone to creating an imbalance in hydrodynamics, which makes it difficult to replace the water in Zhushan Bay and the western lake areas where pollution is serious and algae easily accumulate. The water exchange areas created by dual-source flow were predicted to be $18.84 \%, 16.24 \%$, and $15.02 \%$ higher than when single-source water diversion occurs in the same areas during the springsummer, autumn, and winter seasons. These changes may enhance the hydrodynamics of the western lake region under the influence of the southeastern monsoon in spring and summer; meanwhile, the hydrodynamics of Zhushan and Meiliang bays are under the influence of the northwestern monsoon in winter. Consequently, taking into account both economic benefits of a dual-source system and local meteorological conditions, it is vital that appropriate methods of water diversion be chosen in accordance with the needs of different periods.

By conducting a statistical analysis of the eight major sublake areas of Tai Lake, we found that the water exchange rate and the semiexchange period of the eight districts under ten operating modes would change significantly. The results of the present study show the wind field has a significant impact on the spatiotemporal water exchange rate and the semiexchange period (Table $3, e, g$, and $i$ and $f, h$, and $j$ ), which is consistent with the conclusion of Safak [38]. The most significant change for the East Lake District would occur when single-source water diversion is carried out in the Wangyu River during winter. Its semiexchange period would be 29-30 days, i.e., 60 days of water diversion can completely replace the water volume of the East Lake District, which is unfavorable to the stability of the ecosystem of the East Lake District [39]. However, if dualsource water diversion is adopted in winter for optimization purposes, the water exchange period would increase to 102 days, which would significantly reduce the negative impact on the eastern lake region. The joint-source diversion 


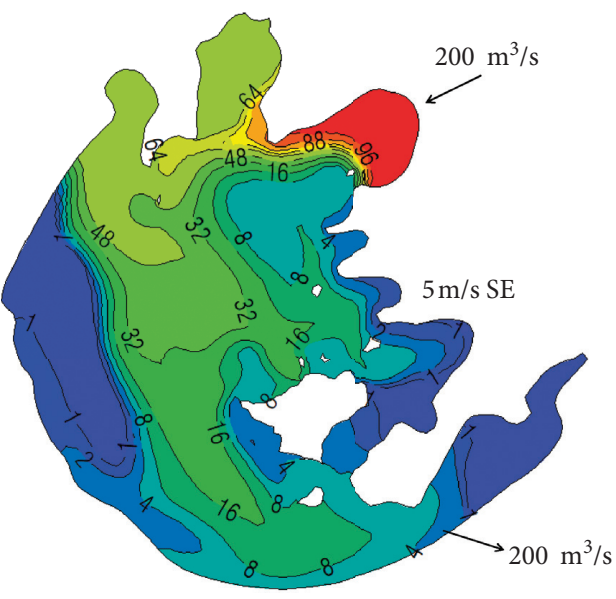

(a)

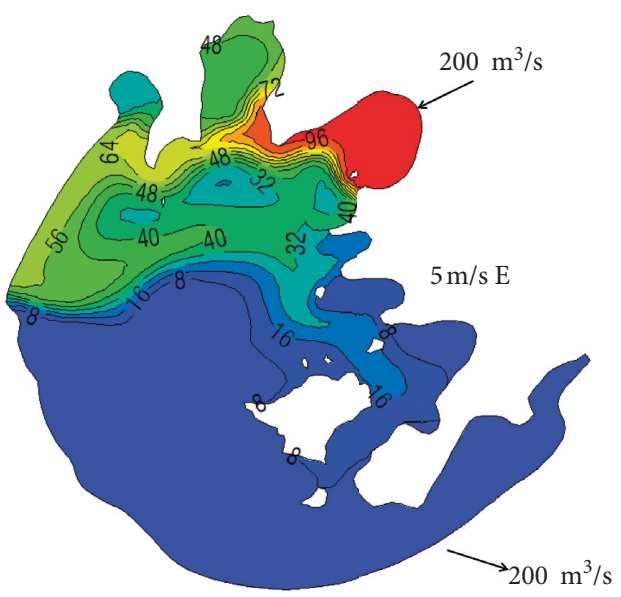

(c)

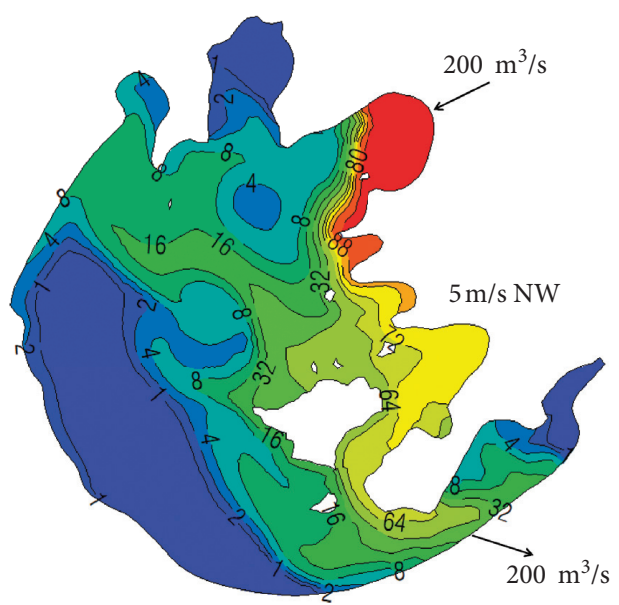

(e)

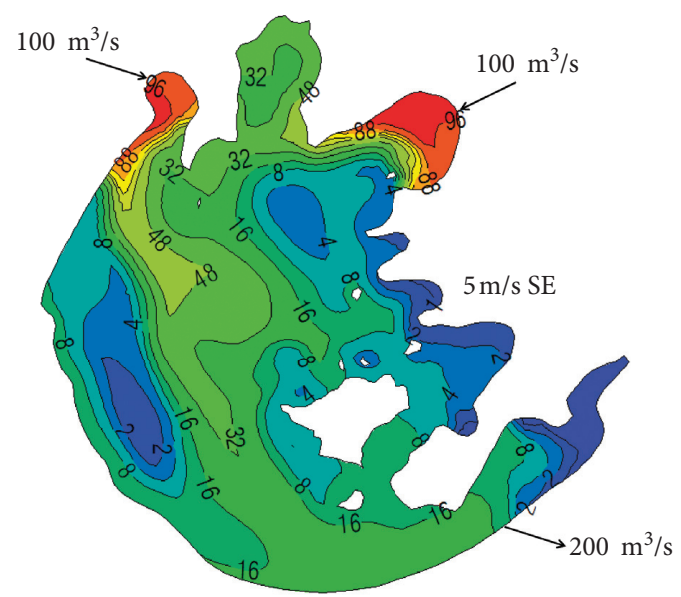

(b)

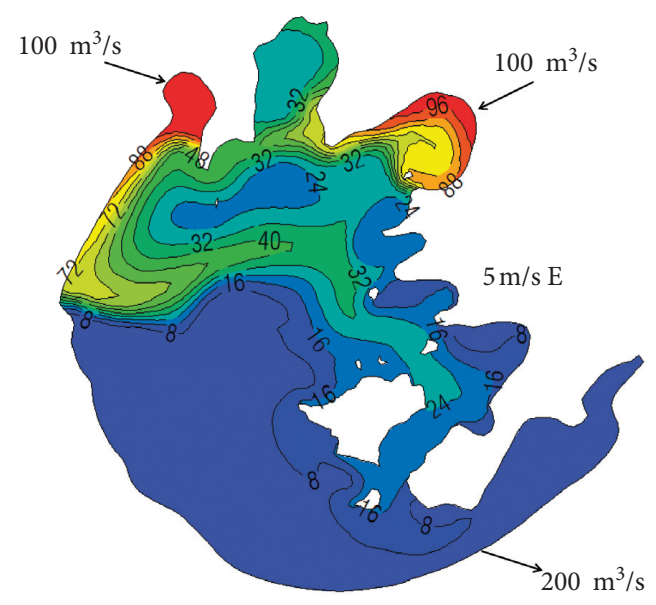

(d)

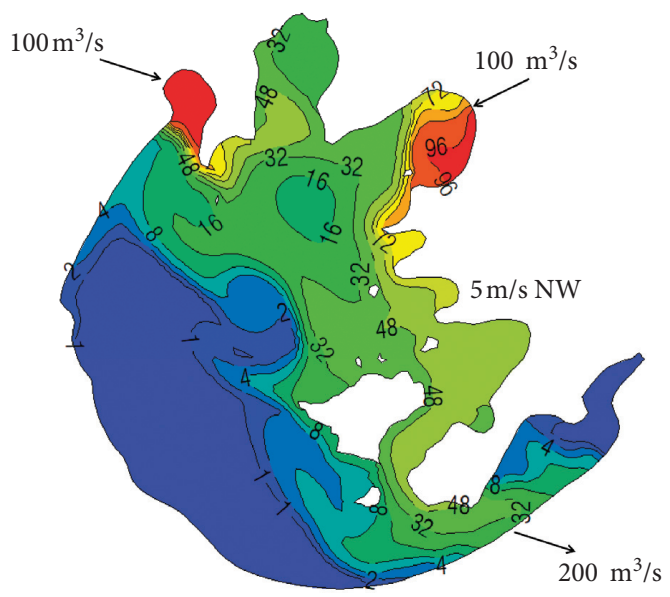

(f)

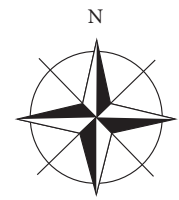

Exchange rate (\%)

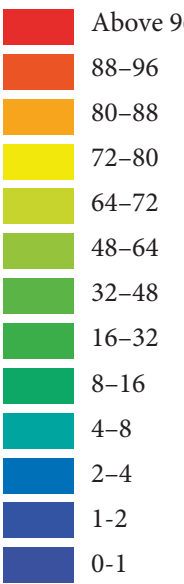

Figure 8: Water exchange rate simulation results for operating modes (e)-(j).

method for the Wangyu-Xingeng rivers should, therefore, be adopted in winter, with each river water volume accounting for half of the total amount of diverted water. During spring and summer, different methods of diversion of water should be applied in accordance with the actual need to replace the water body in particular areas. Specifically, when an exchange of water is required in the Meiliang Bay area, a single-source diversion method is recommended for the Wangyu River; when an exchange of water is required in the western lake area, the Wangyu River-Xingeng River jointsource diversion method should be adopted with $50 \%$ of the water contributed by the Wangyu River. In autumn, sewage 
TABLE 3: Water exchange rate and the semiexchange period of eight lake districts under ten operating modes.

\begin{tabular}{|c|c|c|c|c|c|c|c|c|c|}
\hline Scene & Indicator & Gong Bay & Meiliang Bay & Zhushan Bay & Center area & Northwest area & Southwest area & East Lake & East area \\
\hline \multirow[b]{2}{*}{$\mathrm{a}$} & EX (\%) & 100 & 21.07 & 0.32 & 29.51 & 0 & 0 & 5.58 & 0 \\
\hline & SEP (day) & $7-8$ & - & - & - & - & - & - & - \\
\hline \multirow{2}{*}{$\mathrm{b}$} & EX (\%) & 99.72 & 8.69 & 99.99 & 15.25 & 53.99 & 0 & 0.54 & 0 \\
\hline & SEP (day) & $16-17$ & - & $5 \sim 6$ & - & $54 \sim 55$ & - & - & - \\
\hline \multirow{2}{*}{ c } & EX (\%) & 100 & 32.32 & 9.27 & 62.27 & 3.72 & 0.01 & 45.68 & 0 \\
\hline & SEP (day) & $3-4$ & - & - & $48 \sim 49$ & - & - & - & - \\
\hline \multirow{2}{*}{ d } & EX (\%) & 100 & 20.43 & 100 & 43.32 & 89.76 & 2.69 & 16.58 & 0 \\
\hline & SEP (day) & $8-9$ & - & $3 \sim 4$ & - & $37 \sim 38$ & - & - & - \\
\hline \multirow{2}{*}{$\mathrm{e}$} & EX (\%) & 65.60 & 59.08 & 55.19 & 9.64 & 9.33 & 1.52 & 3.35 & 1.57 \\
\hline & SEP (day) & $8-9$ & $47 \sim 48$ & $53 \sim 54$ & - & - & - & - & - \\
\hline \multirow{2}{*}{$\mathrm{f}$} & EX (\%) & 51.60 & 35.93 & 77.97 & 9.91 & 19.46 & 11.68 & 4.74 & 7.63 \\
\hline & SEP (day) & $53-54$ & - & $9 \sim 10$ & - & - & - & - & - \\
\hline \multirow[b]{2}{*}{ g } & EX (\%) & 83.07 & 55.15 & 50.43 & 17.73 & 40.28 & 0.32 & 12.73 & 0 \\
\hline & SEP (day) & $8-9$ & $52 \sim 53$ & $59 \sim 60$ & - & - & - & - & - \\
\hline \multirow{2}{*}{$\mathrm{h}$} & EX (\%) & 64.43 & 36.78 & 83.15 & 18.62 & 47.08 & 1.24 & 19.01 & 2.47 \\
\hline & SEP (day) & $34-35$ & - & $8 \sim 9$ & - & - & - & - & - \\
\hline \multirow{2}{*}{ i } & EX (\%) & 72.74 & 7.81 & 30.57 & 18.55 & 3.82 & 1.66 & 70.49 & 20.19 \\
\hline & SEP (day) & $7-8$ & - & - & - & - & - & $29 \sim 30$ & - \\
\hline \multirow[t]{2}{*}{ i } & EX (\%) & 68.68 & 36.19 & 80.09 & 19.18 & 2.22 & 0.77 & 54.93 & 12.91 \\
\hline & SEP (day) & $18-19$ & - & $6 \sim 7$ & - & - & - & $50 \sim 51$ & - \\
\hline
\end{tabular}

" " means that the semiexchange period (SEP) has not been reached within the calculation time and no value is assigned.

TABLE 4: Three optimal water diversion strategies.

\begin{tabular}{lcccc}
\hline Strategy & Wangyu River $\left(\mathrm{m}^{3} / \mathrm{s}\right)$ & Xinmeng River $\left(\mathrm{m}^{3} / \mathrm{s}\right)$ & Wind field & Index optimization \\
\hline 1 & 100 & 100 & Windless & Flow rate \\
2 & 200 & 0 & E, SE $(4 \mathrm{~m} / \mathrm{s})$ & Evenness for the east part of Tai Lake \\
3 & 100 & 100 & NW $(4 \mathrm{~m} / \mathrm{s})$ & Evenness for the east part of Tai Lake \\
\hline
\end{tabular}

from the western part of the lake would flow rapidly to the East Lake District under the influence of the easterly wind flow. In this case, a single-source water diversion of the Wangyu River should be undertaken so that pollutants in the heart of the lake can be neutralized and the impact on the ecosystem of the East Lake District can be reduced.

Using the modeled results above, all strategies were analyzed according to the flow rate and uniformity index [40]. It was found that more attention should be paid to the effects of the flow rate, which will change the stability of the ecosystem. When the wind field dominates the flow field, more attention should be paid to the water exchange uniformity index, which will have a significant impact on the large forms of wetland vegetation [2]. Finally, this study sets out the scientifically sound management strategies (Table 4) for the "DWYRTL" project based on the specific conditions of the wind field.

\section{Conclusions}

First, an appropriate type of water body diversion can improve the water quality of Tai Lake. Excessive diversion of water would, however, dramatically alter the local flow fields, which would not be conducive to the growth of aquatic plants and the stability of various parts of the Tai Lake ecosystem. Excessive diversion would also have serious effects on the original storage capacity and the natural ability of the lake to adjust to various types of changing conditions.
Therefore, the WDYRTL project should not unintentionally expand the scale of water diversion in the future. It is recommended that the total annual diversion of water should not exceed $20 \%$ of the total intake of water, i.e., $20 \times 10^{8} \mathrm{~m}^{3} / \mathrm{a}$. The optimization of water management can be carried out by combining weather forecast information with the dual-source water diversion mode.

Second, the exchange rate of water depends mainly on the amount of water entering/exiting the lake. Ignoring wind conditions, the flow rate of a single-source water diversion is approximately $50 \%$ higher than that of dual-source water diversion. In southeastern monsoon conditions, the exchange of water occurs mainly in three lake bay areas and in the center of the lakes. Under the conditions of the east monsoon, water exchange rates will be the highest in three lake bay areas and the Northwest Lake area. Meanwhile, during the northwest monsoon, water exchange will primarily occur in the Center and East Lake districts. In a sense, the wind field is predicted to be the key factor determining the spatiotemporal distribution of the water exchange area.

Third, under normal conditions, the dual-source water diversion method has many more advantages than the single-source water diversion method; however, some differences would recommend use of the single-source method at times. In spring and summer, single-and double-source water diversion methods should be selected based on the needs of the actual water replacement areas. In autumn, a single-source water diversion method is preferable to ensure 
both an adequate water supply in the West Lake area and the stability of the aquatic ecosystem in the East Lake area. In winter, the Wangyu-Xinmeng River dual-source water diversion method is recommended, with each river accounting for $50 \%$ of the total amount diverted water.

\section{Data Availability}

The other data used to support the findings of this study are included within the article.

\section{Conflicts of Interest}

The authors declare that they have no conflicts of interest.

\section{Acknowledgments}

The authors thank the Chinese National Science Foundation (Grant no. 51879070). This work was supported by "the Fundamental Research Funds for the Central Universities and the World-Class Universities (Disciplines) and the Characteristic Development Guidance Funds for the Central Universities". This research was also funded by the Major Science and Technology Program for Water Pollution Control and Treatment of China (Grant no. 2018ZX07208007). The authors thank LetPub (http://www. letpub.com) for its linguistic assistance during the preparation of this manuscript.

\section{References}

[1] Y. Qin, Q. Wen, Y. Ma, C. Yang, and Z. Liu, “Antibiotics pollution in gonghu bay in the period of water diversion from Yangtze River to Taihu lake," Environmental Earth Sciences, vol. 77, pp. 1-11, 2018.

[2] Y. Pan, L. Jin, Z.-H. Wei et al., "Experimental evidence that water-exchange unevenness affects individual characteristics of two wetland macrophytes Phalaris arundinacea and Polygonum hydropiper," Ecological Indicators, vol. 107, p. 105617, 2019.

[3] A. B. G. Janssen, V. C. L. de Jager, J. H. Janse et al., "Spatial identification of critical nutrient loads of large shallow lakes: implications for Lake Taihu (China)," Water Research, vol. 119, pp. 276-287, 2017.

[4] Q. Zhang, Y.-S. Xu, L. Huang et al., "Does mechanical disturbance affect the performance and species composition of submerged macrophyte communities?" Scientific Reports, vol. 4, no. 1, p. 4888, 2015.

[5] H. Gao, X. Qian, H. Wu, H. Li, H. Pan, and C. Han, "Combined effects of submerged macrophytes and aquatic animals on the restoration of a eutrophic water body-A case study of Gonghu Bay, Lake Taihu," Ecological Engineering, vol. 102, pp. 15-23, 2017.

[6] P. Zhang, R.-F. Liang, P.-X. Zhao et al., "The hydraulic driving mechanisms of cyanobacteria accumulation and the effects of flow pattern on ecological restoration in lake dianchi caohai," International Journal of Environmental Research and Public Health, vol. 16, no. 3, p. 361, 2019.

[7] T. Wu, B. Qin, J. D. Brookes et al., "The influence of changes in wind patterns on the areal extension of surface cyanobacterial blooms in a large shallow lake in China," Science of The Total Environment, vol. 518-519, pp. 24-30, 2015.
[8] X. Zhang, R. Zou, Y. Wang et al., "Is water age a reliable indicator for evaluating water quality effectiveness of water diversion projects in eutrophic lakes?" Journal of Hydrology, vol. 542, pp. 281-291, 2016.

[9] Y. Li, J. Simůnek, S. Wang, W. Zhang, and J. Yuan, "Simulating the effects of lake wind waves on water and solute exchange across the lakeshore using hydrus-2D," Water, vol. 9, no. 8, p. 566, 2017.

[10] F. Christian, R. Arturas, G. Saulius, U. Georg, and B. Lina, "Hydraulic regime-based zonation scheme of the Curonian Lagoon,” Hydrobiologia, vol. 611, no. 1, pp. 133-146, 2008.

[11] R. Luff and T. Pohlmann, "Calculation of water exchange times in the ICES-boxes with a eulerian dispersion model using a half-life time approach," Deutsche Hydrographische Zeitschrift, vol. 47, no. 4, pp. 287-299, 1995.

[12] K. Cui-ping, D. Zhi-chao, G. Jie, Z. Hua-ming, and Z. Wei, "Impact of dredging project on water exchange of Qilihai Lagoon wetland," China Environmental Science, vol. 39, pp. 343-350, 2019.

[13] P. A. Lozovik, M. B. Zobkov, G. S. Borodulina, and I. V. Tokarev, "Effects of external water exchange between bays of lakes on chemical indicators of water," Vodnye Resursy, vol. 46, pp. 91-101, 2019.

[14] A. Cucco, G. Umgiesser, C. Ferrarin, A. Perilli, D. M. Canu, and C. Solidoro, "Eulerian and Lagrangian transport time scales of a tidal active coastal basin," Ecological Modelling, vol. 220, no. 7, pp. 913-922, 2009.

[15] M. X. Xie, M. G. Li, M. Y. Mai, and W. D. Li, "Numerical modeling of the water exchange ability of the artificial lake at Taiping Bay Harbor, Dalian," Journal of Waterway and Harbor, vol. 39, pp. 17-24, 2018.

[16] J. Dai, S. Wu, X. Wu et al., "Effects of water diversion from Yangtze River to lake Taihu on the phytoplankton habitat of the Wangyu River channel," Water, vol. 10, no. 6, p. 759, 2018.

[17] L. Xu, X. Gao, C. Zhang, and C. Wang, "Numerical simulation-based study on exchange of water in urban artificial lake," Water Resources and Hydropower Engineering, vol. 49, pp. 94-100, 2018.

[18] Y. Li, C. Tang, J. Zhu et al., "Parametric uncertainty and sensitivity analysis of hydrodynamic processes for a large shallow freshwater lake," Hydrological Sciences Journal, vol. 60, no. 6, pp. 1078-1095, 2015.

[19] Y. Li, C. Tang, C. Wang et al., "Assessing and modeling impacts of different inter-basin water transfer routes on Lake Taihu and the Yangtze River, China," Ecological Engineering, vol. 60, pp. 399-413, 2013.

[20] Q. Yang, S. Wu, J. Dai, X. Wu, W. Xue, and F. Liu, "Effects of short-term water diversion in summer on water quality and algae in Gonghu Bay, Lake Taihu." Journal of Lake Sciences, vol. 30, pp. 34-43, 2018.

[21] G. Qing, "Research on influence of Xinmeng River dredging and extending project on water environment of Yangtze River," Yangtze River, vol. 47, p. 20, 2016.

[22] Z. Yong, "Research on effects of water diversion and drainage engineering on water environment improvement in Taihu lake-a case of Xinmeng river," Pearl River, vol. 4, pp. 37-40, 2014.

[23] A. Jalil, Y. Li, K. Zhang et al., "Wind-induced hydrodynamic changes impact on sediment resuspension for large, shallow Lake Taihu, China," International Journal of Sediment Research, vol. 34, no. 3, pp. 205-215, 2019.

[24] L. Jiang, Y. Li, X. Zhao et al., "Parameter uncertainty and sensitivity analysis of water quality model in Lake Taihu, China," Ecological Modelling, vol. 375, pp. 1-12, 2018. 
[25] Z. Yan, H. Yang, H. Dong et al., "Occurrence and ecological risk assessment of organic micropollutants in the lower reaches of the Yangtze River, China: a case study of water diversion," Environmental Pollution, vol. 239, pp. 223-232, 2018.

[26] L. Zhu, R. Hu, H. Zhu, S. Jiang, Y. Xu, and N. Wang, "Modeling studies of tidal dynamics and the associated responses to coastline changes in the Bohai Sea, China," Ocean Dynamics, vol. 68, no. 12, pp. 1625-1648, 2018.

[27] H. Wang, M. Wu, Y. Deng, C. Tang, and R. Yang, "Surface water quality monitoring site optimization for Poyang Lake, the largest freshwater lake in China," International Journal of Environmental Research and Public Health, vol. 11, no. 11, pp. 11833-11845, 2014.

[28] R. Xu, Y. Pang, Z. Hu, T. Zhu, and J. P. Kaisam, "Influence of water diversion on spatial and temporal distribution of flow field and total phosphorus (TP) concentration field in Taihu Lake," Water Supply, vol. 20, no. 3, pp. 1059-1071, 2020.

[29] J. Huang, Q. Xu, B. Xi et al., "Impacts of hydrodynamic disturbance on sediment resuspension, phosphorus and phosphatase release, and cyanobacterial growth in Lake Tai," Environmental Earth Sciences, vol. 74, no. 5, pp. 3945-3954, 2015.

[30] Y. Li, S. Zhou, Z. Jia et al., "Influence of industrialization and environmental protection on environmental pollution: a case study of Taihu lake, China," International Journal of Environmental Research and Public Health, vol. 15, no. 12, p. 2628, 2018.

[31] J. Wang, Q. Zhao, Y. Pang, Y. Li, Z. Yu, and Y. Wang, "Dynamic simulation of sediment resuspension and its effect on water quality in Lake Taihu, China," Water Supply, vol. 17, no. 5, pp. 1335-1346, 2017.

[32] M. Kong, J. Chao, W. Zhuang et al., "Spatial and temporal distribution of particulate phosphorus and their correlation with environmental factors in a shallow eutrophic Chinese lake (lake Taihu)," International Journal of Environmental Research and Public Health, vol. 15, no. 11, p. 2355, 2018.

[33] J. Yao, Y. Li, D. Zhang, Q. Zhang, and J. Tao, "Wind effects on hydrodynamics and implications for ecology in a hydraulically dominated river-lake floodplain system: poyang Lake," Journal of Hydrology, vol. 571, pp. 103-113, 2019.

[34] A. Jalil, Y. Li, W. Du et al., "Wind-induced flow velocity effects on nutrient concentrations at Eastern Bay of Lake Taihu, China," Environmental Science and Pollution Research, vol. 24, no. 21, pp. 17900-17911, 2017.

[35] D.-y. Yuan, X. Meng, C.-q. Duan et al., "Effects of water exchange rate on morphological and physiological characteristics of two submerged macrophytes from Erhai Lake," Ecology and Evolution, vol. 8, no. 24, pp. 12750-12760, 2018.

[36] J.-P. Descy, F. Leprieur, S. Pirlot et al., "Identifying the factors determining blooms of cyanobacteria in a set of shallow lakes," Ecological Informatics, vol. 34, pp. 129-138, 2016.

[37] A. Jalil, Y. Li, W. Du et al., "The role of wind field induced flow velocities in destratification and hypoxia reduction at Meiling Bay of large shallow Lake Taihu, China," Environmental Pollution, vol. 232, pp. 591-602, 2018.

[38] I. Safak, P. L. Wiberg, D. L. Richardson, and M. O. Kurum, "Controls on residence time and exchange in a system of shallow coastal bays," Continental Shelf Research, vol. 97, pp. 7-20, 2015.

[39] F. Li, Y. Pan, Y. Xie et al., "Different roles of three emergent macrophytes in promoting sedimentation in Dongting Lake, China," Aquatic Sciences, vol. 78, no. 1, pp. 159-169, 2015.
[40] C. Tang, Y. Yi, Z. Yang, S. Zhang, and H. Liu, "Effects of ecological flow release patterns on water quality and ecological restoration of a large shallow lake," Journal of Cleaner Production, vol. 174, pp. 577-590, 2018. 